\title{
PEMBUATAN SURFAKTAN SODIUM LIGNO SULFONAT DARI AMPAS TEBU
}

\author{
Farham HM.Saleh $^{1)}$, Andhika Dwi Cahaya Jumail' ${ }^{2)}$, Fajrul Muhajirin ${ }^{2)}$ \\ Jurusan Teknik Kimia Fakultas Teknologi Industri Universitas Islam Indonesia ${ }^{1,2,3)}$, \\ Jl.Kaliurang Km.14,5, Sleman, Yogyakarta. \\ Email:farham.saleh@gmail.com ${ }^{1)}$
}

\begin{abstract}
Bagasse is one of the agricultural waste which is quite high at 19.7\%. This research aims to assess the possibility of the use of bagasse as raw material for the manufacture of surfactants. Variable research is the concentration of $\mathrm{NaHSO}_{3}$ and long reaction time. The research was conducted using a three-neck flask reactor operated at $105^{\circ} \mathrm{C}$ and $\mathrm{pH}$ 4. Bagasse was pulverized to 120 mesh size, extracted with methanol for isolation of lignin. Furthermore, lignin reacted with $\mathrm{NaHSO}_{3}$ in a threeneck flask at $105^{\circ} \mathrm{C}$ and $\mathrm{pH}$ 4. The results showed that the greater the concentration NaHSO3 and the longer the reaction time, the amount of lignosulfonates produced even greater. The optimum condition was obtained at a concentration of $30 \% \mathrm{NaHSO}_{3}$ and the long reaction time of 60 minutes to produce the amount of lignosulfonate 17209.238 ppm or a yield of $20.717 \%$.
\end{abstract}

Keywords : Surfactants, Bagasse.

\section{PENDAHULUAN}

Saat ini kebutuhan surfaktan di Indonesia semakin meningkat seiring dengan perkembangan industri deterjen. Menurut peneliti dari Puslit Kimia LIPI (Lembaga Ilmu Pengetahuan Indonesia) Wuryaningsih (2006), kebutuhan surfaktan di Indonesia sekitar 95000 ton per tahun, sedangkan kapasitas produksi dalam negeri sekitar 55000 ton per tahun.Ini berarti bahwa Indonesia saat sekarang masih mengimpor sekitar 44500 ton. Umumnya surfaktan yang digunakan pada saat sekarang diproduksi dari bahan baku residu minyak bumi, yang dapat dikatakan kurang ramah lingkungan dan kurang ramah untuk manusia. Selain itu perlu diketahui bahwa cadangan minyak bumi didunia saat ini sudah semakin menipis. Oleh karena itu untuk memenuhi kebutuhan surfaktan di Indonesia, perlu dipelajari pemanfaatan limbah pertanian sebagai bahan baku pembuatan surfaktan.

Beberapa peneliti terdahulu melakukan penelitian pembuatan surfaktan dari limbah pertanian di antaranya Sri Wahyu Murni, dkk (2013), Apris K dan Kukuh BS (2015) serta Mukti M, Eny S dan Arief W (2015). Sri Wahyu Murni, dkk (2013) meneliti pendirian pabrik pembuatan surfaktan dari limbah jerami padi dan menyimpulkan bahwa dengan reaktan 2,5 gram lignin hasil sulfonasi dan menghasilkan 2,5509 gram sodium lignosulfonat (SLS). Kemudian Apris K dan Kukuh BS (2015) meneliti pembuatan surfaktan dari tempurung kelapa dan menyimpulkan bahwa konsentrasi surfaktan maksimal pada penggunaan natrium bisulfit dengan konsentrasi 30\% dan perbanding reaktan 3:5. Selanjutnya Mukti M, Eny S dan Arief W (2015) meneliti pendirian pabrik pembuatan surfaktan dari debu sabut kelapa (2015) dan menyimpulkan bahwa pabrik dapat didirikan Break Even Point (BEP) 55\%, Internal Rate of Return (IRR) $53 \%$ dan Pay Out Time (POT) 5 Tahun. Pada penelitian ini dilakukan pembuatan surfaktan dengan bahan baku limbah ampas tebu.

Tebu merupakan bahan bakuyang digunakan pada pabrik gula. Pada proses pembuatan gula akan dihasilkan limbah berupa ampas tebu. Pada umumnya, pabrik gula di Indonesia hanya memanfaatkan ampas tebu sebagai bahan bakar bagi pabrik yang bersangkutan. Ampas tebu (bagasse) merupakan hasil samping dari proses ekstraksi cairan tebu. Dari suatu pabrik dapat 
dihasilkan sekitar 35 - 40\% dari berat tebu digiling. Tanaman tebu umumnya menghasilkan $24-36 \%$ bagasse tergantung pada kondisi dan macamnya. Bagasse mengandung air $48-52 \%$, gula $2,5-6 \%$ dan serat $44-48 \%$. Di dalam serat terkandung lignin. Lignin adalah senyawa organik polimer yang banyak dan penting dalam dunia tumbuhan selain selulosa. Lignin merupakan suatu phenolic polimer yang menyebabkan kekuatan dan rigidity pada dinding sel tanaman berkayu. Tebu mengandung lignin sebesar 19,7 \%. (Othmer, 1981), sedangkan ampas tebu (baggase) mengandung lignin sebesar 22,09\% (Husin, 2007).

Surfaktan (surface active agent) atau bahan aktif permukaan merupakan suatu zat yang ditambahkan pada cairan untuk meningkatkan sifat penyebaran atau pembasahan dengan menurunkan tegangan permukaan cairan khususnya air. Surfaktan banyak digunakan dalam industri antara lain sebagai corrosion inhibitor, deterjen, emulgator, dan hair conditioner. Pada eksplorasi minyak bumi, jumlah minyak bumi yang dipungut dapat ditingkatkan dengan injeksi surfaktan. Surfaktan dapat dibuat dengan proses sulfonasi lignin menggunakan Natrium Bisulfit $\left(\mathrm{NaHSO}_{3}\right)$, yang menghasilkan Sodium Ligno Sulfonat (SLS).

Penelitian ini bertujuan untuk membuat SLS dengan memanfaatkan ampas tebu sebagai bahan baku, yang direaksikan dengan Natrium Bisulfit. Dengan variabel penelitian berupa konsentrasi larutan Natrium Bisulfit dan waktu reaksi, akan ditentukan kondisi optimum yang dapat menghasilkan kadar surfaktan terbesar.

\section{METODE PENELITIAN}

Bahan - bahan yang digunakan dalam penelitian ini adalah ampas tebu, Natrium Bisulfit $\left(\mathrm{NaHSO}_{3}\right)$, asam sulfat $\left(\mathrm{H}_{2} \mathrm{SO}_{4}\right)$, aquades $\left(\mathrm{H}_{2} \mathrm{O}\right)$, methanol $\left(\mathrm{CH}_{3} \mathrm{OH}\right)$ dan Linier Alkyl Benzene Sulfonate (LAS). Adapun alat - alat yang digunakan dalam penelitian diantaranya labu leher tiga, kondenser, motor pengaduk, impeller, kertas
$\mathrm{pH}$ universal, thermometer, gelas ukur, spatula, timbangan, pipet ukur, pipet tetes, vibrating screen, crusher, oil bath dan spektrofotometer UV / Vis.

Dalam penelitian ini ditetapkan variabelvariabel konsentasi larutan $\mathrm{NaHSO}_{3}$ dan waktu reaksi. Konsentasi $\mathrm{NaHSO}_{3}$ ditetapkan dalam bentuk kadar sebesar $10 \%$, $20 \%$ dan $30 \%$, sedangkan waktu reaksi ditetapkan selama 30 menit dan 60 menit. Ampas tebu dikupas kulit luarnya, dipotong kecil - kecil dan dijemur pada sinar matahari langsung selama 2 (dua) minggu atau jika dinilai sudah kering.Selanjutnya ampas tebu yang sudah kering dihancurkan dengan crusher secara berulang sehingga menjadi seperti debu. Debu halus ampas tebu kemudian diayak dengan ayakan 120 mesh sehingga diperoleh debu ampas tebu sebanyak kurang lebih $2 \mathrm{~kg}$. Selanjutnya debu ampas tebu sebanyak 10 gram dibungkus kertas saring kemudian dimasukkan ke dalam shoxlet untuk dilakukan ekstraksi dengan methanol. Ekstraksi dilakukan sebanyak 5 sirkulasi selama 1 jam 30 menit. Debu ampas tebu yang telah diekstraksi dalam shoxlet kemudian dikeringkan di oven pada suhu $100{ }^{\circ} \mathrm{C}$ sampai kering.

Debu ampas tebu yang sudah kering sebanyak 7 gram direaksikan dengan Natrium Bisulfit dengan konsentrasi 10\%, $20 \%$ dan $30 \%$ dalam labu leher tiga. Reaksi dikondisikan pada $\mathrm{pH} 4$ dan suhu $105{ }^{0} \mathrm{C}$ dengan waktu reaksi masing - masing 30 menit dan 60 menit untuk masing - masing sampel. Selanjutnya hasil proses reaksi dalam labu leher tiga disaring sehingga diperoleh filtrat dan residu. Filtrat kemudian dianalisis dengan spektrofotometer UV / Vis untuk menentukan kadar lignosulfonat yang dihasilkan. 


\section{HASIL PENELITIAN DAN PEMBAHASAN}

Penelitian dilakukan dengan menggunakan sampel ampas tebu ukuran 120 mesh, dengan variasi waktu pemasakan 30 menit dan 60 menit serta dengan variasi konsentrasi pelarut $\mathrm{NaHSO}_{3}$ yaitu $10 \%, 20$ $\%$, dan $30 \%$ diperoleh hasil sebagaimana ditunjukkan Tabel 1.Tabel 1 menunjukkan bahwa semakin besar konsentrasi Natrium Bisulfit dalam interval variable yaitu $10 \%$ sampai 30\%, jumlah lignosulfonat yang dihasilkan semakin besar, baik pada variabel waktu reaksi 30 menit maupun waktu reaksi 60 menit. Untuk lama waktu reaksi 30 menit dan kadar Natrium Bisulfit 30\%, diperoleh lignosulfonat sebesar $11.950,573 \mathrm{ppm}$ atau dengan yield $14,387 \%$. Untuk lama waktu reaksi 60 menit dan kadar Natrium Bisulfit $30 \%$, diperoleh lignosulfonat sebesar $17.209,238 \mathrm{ppm}$ atau dengan yield 20,717\%. Ini menunjukkan bahwa kondisi terbaik untuk variabel konsentrasi Natrium Bisulfit pada penelitian ini diperoleh pada konsentrasi $30 \%$.

Untuk variabel waktu reaksi, semakin lama waktu reaksi maka semakin besar jumlah lignosulfonat yang dihasilkan. Untuk konsentrasi Natrium Bisulfit 30\%, pada lama waktu reaksi 30 menit diperoleh jumlah lignosulfonat sebesar 11950,573 ppm atau yield sebesar 14,837\%, sedangkan untuk lama waktu reaksi 60 menit diperoleh jumlah lignosulfonat sebesar 17209,238 ppm atau yield sebesar 20, 717\%. Hal ini menunjukkan kondisi optimum diperoleh pada kadar Natrium Bisulfit sebanyak 30\% dan waktu reaksi selama 60 menit yaitu dengan yield sebesar $20,717 \%$.

\section{KESIMPULAN DAN SARAN}

\subsection{Kesimpulan}

Dari hasil penelitian dan pembahasan pada sub bab sebelumnya dapat disimpulkan bahwa :

1. Pada berbagai variabel konsentrasi $\mathrm{NaHSO}_{3}$ waktu reaksi $(10 \%, 20 \%, 30 \%)$, semakin lama waktu reaksi maka semakin besar pula kadar lignosulfonat yang dihasilkan.

2. Pada berbagai variabel lama waktu reaksi (30 menit dan 60 menit), semakin besar konsentrasi $\mathrm{NaHSO}_{3}$ yang digunakan maka kadar lignosulfonat yang dihasilkan juga semakin besar.

3. Pada konsentrasi $\mathrm{NaHSO}_{3} 30 \%$ dan lama waktu reaksi 60 menit, didapatkan kondisi optimum kadar lignosulfonat yaitu sebesar 17.209,238 ppm atau yield sebesar $20,717 \%$.

\subsection{Saran}

Saran yang dapat diberikan untuk penelitian lanjut adalah :

1. Sebaiknya untuk penelitian selanjutnya dapat menambahkan variabel waktu yang lebih bervariasi karena ada kemungkinan semakin lama waktu reaksi dapat menimbulkan penurunan kadar lignosulfonat akibat jenuhnya lignin yang bereaksi dengan $\mathrm{NaHSO}_{3}$.

2. Pada proses reaksi ampas tebu dengan $\mathrm{NaHSO}_{3}$ perlu adanya ketelitian dalam melihat suhu yang ditentukan agar tetap konstan.

3. Perlu lebih teliti dan dikembangkan lebih lanjut agar yield yang dihasilkan dapat diperbesar diantaranya menggunkan peralatan standar untuk mengurangi human error yang terjadi saat melakukan penelitian, seperti menjaga suhu dan kecepatan putaran pengaduk. 
Tabel 1. Pengaruh Perbedaan Waktu dan Konsentrasi $\mathrm{NaHSO}_{3}$ Terhadap Kadar Lignosufonat

\begin{tabular}{|c|c|c|c|c|}
\hline $\begin{array}{c}\text { Waktu } \\
\text { Pemasakan } \\
\text { (Menit) }\end{array}$ & $\begin{array}{c}\text { Konsentrasi } \\
\mathrm{NaHSO}_{3} \\
(\%)\end{array}$ & $\begin{array}{c}\text { Absorbansi } \\
(\lambda=223 \mathrm{~nm})\end{array}$ & $\begin{array}{c}\text { Kadar Lignosulfonat } \\
(\mathrm{ppm})\end{array}$ & $\begin{array}{c}\text { Yield } \\
(\%)\end{array}$ \\
\hline & 10 & 0,361 & 2183,918 & 2,629 \\
& 20 & 0,296 & 7216,472 & 8,688 \\
& 30 & 0,089 & 11950,573 & 14,387 \\
& 10 & 0,074 & 10139,121 & 12,206 \\
& 20 & 0,106 & 13878,505 & 16,708 \\
& 30 & 0,135 & 17209,238 & 20,717 \\
\hline
\end{tabular}

\section{DAFTAR PUSTAKA}

Apris Kurniawan dkk. Kajian awal pembuatan surfaktan dari tempurung kelapa. Universitas Diponegoro : Semarang. (diakses 21 Desember 2015), 2008.

Ari P, Heri dkk. Studi Awal Mengenai Pembuatan Surfaktan dari Ampas Tebu. Universitas Diponegoro : Semarang. (www.research (FORMAT_BARU).Pdf) (di akses November 2015), 2008.

Hayyan, Ibnu. Pengertian Surfaktan / Emulsi. Diakses dari http://ibnuhayyan.wordpress.com (14 Desember 2015), 2008. http://digilib.ump.ac.id/files/disk1/14/jhptum p-a-fitriyani-662-2-babii.pdf (diakses 10 Januari 2016)

http://intanint.blogspot.co.id/2013/12/makal ah-surfaktan.html (akses 3 Januari 2016)

http://repository.usu.ac.id/bitstream/123456 789/17135/4/Chapter\%20II.pdf (diakses 30 Desember 2015) http://repository.usu.ac.id/bitstream/123456 789/19239/4/Chapter\%20II.pdf (diakses 15 Desember 2015)

https://ambhen.wordpress.com/2013/04/16/a mpas-tebu/ (diakses 15 Desember 2015)

https://id.wikipedia.org/wiki/Surfaktan (diakses 30 Desember 2015)
Othmer, D.P. Encyclopedia of Chemical Technology. Fourth Edition, Volume 15. New York (diakses 3 Januari 2016), 1981.

Widodo HS. Permintaan surfaktan Indonesia Sebesar 11,82 Juta Ton Per Tahun dan pertumbuhan permintaan surfaktan rata - rata 3 persen per tahun. Media Indonesia, 2004.

Wuryaningsih. Kebutuhan akan penggunaan surfaktan di Indonesia. Puslit Kimia Lembaga Ilmu Pengetahuan Indonesia. Jakarta, 2006. 